\title{
Five Competitive Forces Model and the Implementation of Porter's Generic Strategies to Gain Firm Performances
}

\author{
Sirajuddin Omsa ${ }^{1}$, Ibrahim H. Abdullah ${ }^{2}$, Hisnol Jamali ${ }^{3}$ \\ ${ }^{1}$ Department of Accounting, State Polytechnic of Ujung Pandang, Makassar, Indonesia \\ ${ }^{2}$ Department of Management Science, Economic Faculty, Muhammadiyah University, Mataram, Indonesia \\ ${ }^{3}$ Program Pascasarjana (PPS) Magister Manajemen (MM), Sekolah Tinggi Ilmu Ekonomi Makassar (STIEM) Bongaya, Makassar, Indonesia
}

Email address:

sirajud_om@yahoo.com (S. Omsa)

\section{To cite this article:}

Sirajuddin Omsa, Ibrahim H. Abdullah, Hisnol Jamali. Five Competitive Forces Model and the Implementation of Porter's Generic Strategies to Gain Firm Performances. Science Journal of Business and Management. Vol. 5, No. 1, 2017, pp. 9-16. doi: 10.11648/j.sjbm.20170501.12

Received: December 29, 2016; Accepted: January 9, 2017; Published: January 26, 2017

\begin{abstract}
Five competitive forces that comprise bargaining power of buyers, bargaining power of suppliers, threat of new entrants, threat of substitute products or services, and intensity of rivalries have been studied by many researchers for several years. However, linking them with Porter's generic strategy in order to gain financial and market performance in the Micro, Small and Medium Enterprises (MSMEs) context is very rare. The main purpose of this study is to analyze how those five competitive forces affect generic strategies developed by Porter and how the generic strategies affect firm performances. Questionnaire, survey and deep interview were conducted to figure out the implemented generic strategies by the owners of MSMEs of wooden furniture in East Java, Indonesia. Smart partial least square (PLS) was used to analyse the data. The results show that power of buyers (PoB) significantly affects only differentiation strategy (DS), power of supplies (PoS) significantly affects cost leadership strategy (CLS) and focus strategy (FS) but does not significantly affect differentiation strategy (DS), and threat of rivalries (ToR) significantly affects differentiation strategy (DS) and focus strategy (FC). In regards to the relationship between generic strategies and firm performances (FP), the results of this study show that both DS and FS significantly affect FP, while CLS does not significantly affect FP. Based on these findings, it is suggested that the owners of MSMEs wooden furniture in East Java (Indonesia) consider PoB, PoS, and ToR before performing DS and FS to gain much greater firm performances in the future.
\end{abstract}

Keywords: Power of Buyers, Power of Suppliers, Threat of Rivalries, Cost Leadership Strategy, Differentiation Strategy, Focus Strategy, Firm Performance

\section{Introduction}

East Java province is the largest furniture manufacturers in Indonesia because approximately $60 \%$ of Indonesia's furniture exports come from this province [8]. In 2015, wooden furniture business sector and other wood products accounted for $6.03 \%$ of the total non-oil exports in East Java [17]. Contributions of wooden furniture from East Java is certainly large enough to get attention from all stakeholders such as central government through related ministries, local governments, chambers of commerce and industry, associations and rattan furniture Indonesia (AMKRI), and other stakeholders. In regards to the problems faced by many business of wooden furniture, the role of stakeholders increasingly important in order to avoid wooden furniture from degradation or even insolvent due to its inability to face economic turmoil that increasingly hostile. In managing large-wooden furniture businesses, Government of Indonesia should learn from other countries whose export value in furniture products constantly increase by year to year such as China and Finland. Indonesia actually has potential growth in wooden furniture export, but the lack of seriousness in handling this type of business leads to the export value lower than those of wooden furniture from Vietnam and Malaysia. According to Omsa et al. (2015) [18], these two countries have not entered yet the top 10 exporters of wooden furniture in the world around 7 years ago.

In the context of micro, small, and medium enterprises (MSMEs) of wooden furniture, East Java Province is also 
encountering some obstacles to facilitate the MSMEs of wooden furniture in increasing financial and market performance. Since the central government of Indonesia strictly enforces the regulation against illegal logging, some MSMEs of wooden furniture found it difficult to access or to find good quality logs. Consequently the price of woods and wooden furniture became more expensive. Some skilled joiners in East Java were also reluctant to work in MSMEs due to the low salaries. Consequently many MSMEs of wooden furniture were difficult to find out skilled carpenters. Omsa et al. (2015) [18] believe that raw material (woods) and employees (skilled joiners) are essential for MSMEs to gain financial and market performances. However, good raw material quality and qualified employees should also be supported by right business strategy if the companies wish to achieve higher performance levels [7].

The main purpose of this article is to analyse the effect of industrial competitive forces that comprises power of buyers (Pob), power of suppliers (PoS), and threat of rivalries (ToR) on the implementation of generic strategies that consist of cost leadership strategy (CLS), differentiation strategy (DS), and focus strategies (FS) in order to achieve firm performances. This article limits the analysis only on three competitive forces since the wooden furniture business in East Java province has strong relationship with those three competitive forces. The article is organized in four main parts. After introduction, the paper discusses deeply the literature review, then analyzes and explains the research result using Smart PLS 3. The conclusion comes up with the recommendation for both business practitioners and for the future research.

\section{Theorical Framework and Research Hypotheses}

Factors that dominate research questions in the field of strategic management is the determinant of the company's performance. Over two decades, experts have been trying to trace the factors that may affect the company's performance. Lahiri (2007) [12] argues that there are three factors that are often of concern in strategic management research, namely industrial influence, corporate influence, and influence of the business unit. Very interesting, because the debate about the influence of the three factors that affect the performance of the company is still going on until now, because of the conclusions related to the right strategy for the company is still not clear, not only for the academics but also for the business practitioners [15].

In 1980, Porter found bargaining power of buyers, bargaining power of suppliers, threat of new entrants, threat of substitute products or services, and intensity of rivalry as the main factors effect on strategic choice by company managers or owners and effect firm performance. Five years later (1985), he found generic strategies that comprise cost leadership, differentiation and focus strategy as the trigger to increase firm performance.
In 2005, Parnell and Hershey (2005) [19] found that management, particularly in the areas of marketing strategy and information systems had become the focus of attention in formulating and implementing business strategies as a driver of corporate performance. Pearce and Robinson (2009) [20] stated that before applying the business strategy, it is important to decide at which level the strategy will be applied. They then split the business coverage into three levels, namely corporate, business unit and functional. This study will focus on the strategy for business unit level which has close links with a competitive strategy that was discovered and developed by Porter.

\section{Competitive Forces, Generic Strategies, and Company Performances}

Competitive forces is defined by Porter (1985) [21] as the pressure of industry on business unit (company/firm/corporate) in gaining performance. According to Porter, the industrial pressures consist of five elements, namely: (1) bargaining power of buyers; (2) bargaining power of suppliers; (3) threat of new entrants; (4) threat of substitute products or services; and (5) rivalry among existing firms. Meanwhile, generic strategy was grouped by Porter into 3 types, such as cost leadership strategy, differentiation strategy, and focus strategy. According to Porter, a business can maximize performance either by striving to be the low cost producer in an industry (cost leadership strategy) or by differentiating its line of products or services from those of other businesses (differentiation strategy); either of these two approaches can be accompanied by a focus of organizational efforts on a given segment of the market (focus strategy).

In regards to the company performances, the main focus of this article is on the financial performance (profit) and market performance (sales volume) of micro, small, and medium size of wooden furniture industries in East Java, Indonesia. The relationship between competitive forces and generic strategies, and competitive forces and firms' performances have been searched by some scholars such as Lahiri (2007) [12], Bordean et al. (2011) [6], Wan and Bullard (2009) [24] and many other business researchers.

Lahiri (2007) [12] found that the intensity of rivalry did not relate with any generic strategy, while the power of clients associated with the differentiation strategy, and the threat of new providers associated with the cost leadership strategy. In his research, Lahiri (2007) [12] did not explain the relationship between the strength of industry competition with the strategy focus, so it cannot be described the shape and strength of relationship between the two variables. Lahiri (2007) [12] conducted a research on outsourcing service providers in India. Furthermore, Wan and Bullard (2009) found that most of the environmental indicators of the industry, such as competition between companies and the pressure of buyers have a significant impact on company to 
gain performance, however threat of new entrants did not have a significant effect on the financial performance of the company.

Yani (2010) [25] explained that the ability to detect the five competitive forces influence the election of generic strategies of Islamic bank in South Kalimantan. Yani (2010) [25] outlined five competitive forces such as competition among existed firms, the entry of new-potential competitors, potential development of substitute products, bargaining power of depositors, and bargaining power of debtors. Ingga (2008) [10] conducted a study on the manufacturing industry in Jakarta Stock Exchange (JSX) agreed with Yani's findings (2010) [25] and confirmed that the industrial competitive forces were positively and significantly impact on cost leadership strategy and differentiation strategy. Ingga also explained that the industrial competitive forces did not affect significantly on competitive advantage.

Long time ago, Porter (1985) [21] stated that when companies are increasingly distressed by the level of competition, the role of strategy becomes more important to enhance the competitiveness of enterprises. The competitiveness of companies is largely determined by their ability to exploit their full potential of their internal capabilities to seize opportunities and face challenges.

Based on the research findings above, several hypotheses can be stated as follows:

Hypothesis 1a: Power of buyers significantly effects cost leadership strategy

Hypothesis 1b: Power of buyers significantly effects differentiation strategy

Hypothesis 1c: Power of buyers significantly effects focus strategy

Hypothesis 2a: Power of suppliers significantly effects cost leadership strategy

Hypothesis 2b: Power of suppliers significantly effects differentiation strategy

Hypothesis 2c: Power of suppliers significantly effects focus strategy

Hypothesis 3a: Threat of rivalries significantly effects cost leadership strategy

Hypothesis 3b: Threat of rivalries significantly effects differentiation strategy

Hypothesis 3c: Threat of rivalries significantly effects focus strategy

\section{Generic Strategies and Company Performances}

Fulfilling Lahiri's research weaknesses, Bordean, Borza, \& Segura (2011) [6] conducted research in San Antonio Hotels, USA and found out that differentiation strategy and focus strategy significantly influenced the San Antonio hotel's performance, while there was no significant effect of cost leadership strategy on hotel's performance. Banker, Mashruwala, and Tripathy (2014) [4] found that both cost leadership and differentiations strategies impact on contemporaneous performance, but the differentiation strategy allows a firm to sustain its current performance in the future to a greater extent than a cost leadership strategy. In contrary, Powers and Hahn (2004) [22] found that in the banking industry it may be difficult to generate superior returns using a differentiation or focus strategy because banks that used competitive methods to pursue a broad differentiation, customer service differentiation, or focus strategy were unable to realize a performance advantage over banks that are stuck-in-the-middle.

According to Baroto, Abdullah, \& Wan (2012) [4], many evidences showed that companies have done very well in a single strategy, for example Wal-Mart and Air Asia are successful companies that have implemented cost leadership strategy. In addition, according to Baroto, Abdullah, \& Wan (2012) [4], several companies have implemented differentiation strategy such as differentiation by Brand (Harley Davidson, and Mercedes Benz); differentiation by design (Titan watches with gold studded gems, diamonds and precious metals), differentiation by positioning: Domino Pizza ("30 minutes delivery"); differentiation by technology (Apple Computers); and differentiation by innovation (3 M). Meanwhile, Analoui and Karami (2002) in Adidam et al. (2012) [1] found that the SMEs which scan the environment prior formulating and implementing their business strategy have better performance than the SMEs that do not perform a scan on the environment. Similarly, Shane and Kolvereid (1995) [23]; Baum et al. (2001) [5]; Herri and Wafa (2003) [9], and Yonggui et al. (2003) [26] found that the industrial environments affect the performance of the company. An interesting result found by Adidam et al. (2012) [1] who stated that Indian firms which exhibit higher level of competitive intelligent activities achieve better financial performance than the moderate or lower level, thereby suggesting an opportunity for performing more sophisticated competitive intelligent techniques.

According to Dauda et al. (2010) [7], strategic management practices enhance both organizational profitability and company market share. This recommends that investors and managers should make use of strategic management to improve their organizations actual performance consistently. Furtherrmore, Karel et al. (2013) [11] found that organizations with well strategy mostly experience positive development in performance, and companies with detailed written strategy indicated mostly fall of their costs. Dauda et al., (2010) [7] also believe that bigger companies pay more attention to strategic management and have more often prepared detailed strategy than smaller enterprises.

Leitner and Guldenberg (2010) [14] revealed that firms that follow a combination strategy outperform companies with no generic strategy in terms of profitability and growth, and they achieve higher profitability than companies that follow a differentiation strategy. However, study by Nandakumar et al. (2011) [16] found out that firms adopting one of the strategies, namely cost-leadership or differentiation perform better than "stuck in the middle" 
firms which do not have a dominant strategy orientation.

Based on the research findings above, the several hypotheses can be stated as follows:

Hypothesis 4a: Cost-leadership strategy significantly effects firm performance

Hypothesis 4b: Differentiation strategy significantly effects firm performance

Hypothesis 4c: Focus strategy significantly affects firm performance

\section{Method of Research}

The data for this study were collected by distributing of structured questionnaires to 305 samples of micro, small and medium enterprises in East Java province. This province is chosen as the site for this study since over fifty percent of national export of wood and wooden furniture contributed by East Java [8]. It implies that East Java can serve as a good representative site for this study.

The independent variables examined in this study is industrial competitive forces that comprises bargaining power of buyers (PoB), bargaining power of suppliers (PoS) and threat from rivalries (ToR). Generic strategies in this case act as intervening variable that break downs into three dimension strategies, namely cost leadership, differentiation, and focus; Finally, as dependent variable firm performances consist of financial performance (profitability) and market performance (sales volume). The questions were tailored along a five point likert scale. The responses were coded and mapped into numeric values; for example, considering the extent of the use of strategic approach in the management of MSMEs. The scale mapping used in this study are: strongly agree $=5$ points, agree $=4$ points, neutral $=3$ points, disagree $=2$ points, strongly disagree $=1$ point [2] Convergent validity and composite realibility were tested using Smart Partial Least Scales (PLS). PLS was also employed on the coded data to determine the relationship among seven latent variables. To sum up, there are three steps have been taken in the research method. Firstly, testing the validity of the data using convergent validty. Secondly, testing the data using composite reliability, where. according to Chin in Latan \& Ghozali (2012) [13], loading factor is assumed to be valid and reliable if it greater than 0.60 . Finally, test the hypothesis using the inner model of the PLS, whereas p-value was used in this study to test the hypotheses. The effect of independent variable on dependent variable is significant if the p-value is lower than 0,05 at the significant level of $5 \%$.

\section{Result and Discussion}

This research involved 305 samples. The copies of the questionnaires were distributed randomly to owners of selected SMEs wooden furniture in East Java, Indonesia. All copies of the questionnaires duly completed and returned were used as the basis of the analysis. The data were examined and analysed using smart PLS 3.

\section{Validity testing with outer loadings}

From table 1, it can be explained that items were valid, only three items were not valid, they were item X121, X122, and X132 with outer loadings $0.431,0,337$ and 0.389 respectively. Therefore, these three items should be dropped, and the rest that above 0,6 validity scores were used in the analysis (insert table 1 here).

Composite reliability

Composite reliability was used in this study to test the reliability of the data. Chin in Latan \& Ghozali (2012) states that unidimensionality from a collection of variables can be assessed using a composite reliability standards for minimum 0.6. All latent variables were reliable since had composite reability scores above 0.6 as shown in table 2 .

Hypotheses testing results

Hypothesis 1a: Power of buyers (PoB) significantly effects cost leadership strategy (CLS)

The hypothesis $1 \mathrm{a}$ is rejected because its $\mathrm{p}$-value is greater than $0,05(0,188)$. This indicates that the implementation of the CLS did not depend on the PoB. In more detail it can be explained that when buyers have sufficient information related to wooden furniture in regards to price, raw materials, models, and quality services and/or buyer have many options similar products in other companies and/or the price factor has great influence on buyers purchasing decision, the owners of wooden furniture do not necessary choose CLS to be implemented. Therefore, the pressure from buyers cannot push the wooden furniture owners to implement CLS. The findings of this study support the findings of Lahiri (2007) [12] and Wan \& Bullard (2009) [24], but are contrary to the findings of Ingga (2008) [10] and Yani (2010) [25].

Hypothesis 1b: Power of buyers (PoB) significantly effects differentiation strategy (DS)

The hypothesis $1 \mathrm{~b}$ is accepted because it's p-value is lower than $0,05(0,00)$. This implies that pressure from buyers can direct the wooden furniture owners to implement DS. The pressure from buyers might in terms of the knowledge they have in regards to the price, raw materials, models, and quality service or could form of the similar products that offer by competitors, so the buyers have many options in choosing desired wooden furniture. When the pressure from buyers increase, the owners will choose DS to be implemented such as produce better product quality, more attractive products, more varieties of products, and provide better service quality. The findings of this study support the findings of Lahiri (2007) [12], Wan \& Bullard (2009) [24] and Ingga (2008) [10], but are contrary to the findings of Leitner \& Guildenberg (2010) [14].

Hypothesis 1c: Power of buyers (PoB) significantly effects focus strategy (FS)

The hypothesis $1 \mathrm{c}$ is rejected because it's p-value greater than $0,05(0,769)$. This indicates that the implementation of the FS did not depend on the PoB. In more detail can be explained that the adequate information by buyers relate to wooden furniture such as quality services, models, price, and raw materials, and/or buyer have many options to choose similar products in other companies and/or the price factor 
has big influence on buyers purchasing decision, the owners of wooden furniture did not necessary decide to implement FS. Therefore, the pressure from buyers cannot direct the owners to produce unique design of wooden furniture or to serve certain consumers. The findings of this study support the findings of Lahiri (2007), but are contrary to the findings of Ingga (2008) and Yani (2010).

Hypothesis 2a: Power of suppliers (PoS) significantly effects cost leadership strategy (CLS)

The hypothesis $2 \mathrm{a}$ is accepted because it's p-value is lower than $0,05(0,001)$. This implies that pressure from suppliers can direct the wooden furniture owners to implement CLS. The pressure from suppliers may increase if the number of suppliers in the industry is limited (less than three), no tight competition among suppliers, and suppliers sale their raw materials to many companies. When the pressure from suppliers is high the owners of the wooden furniture will cut the cost of raw materials, of auxiliary materials, and of labors. The findings of this study support the findings of Lahiri (2007) [12], but are contrary to the findings of Bordean et al. (2011) [6].

Hypothesis 2b: Power of suppliers (PoS) significantly effects differentiation strategy (DS)

The hypothesis $2 \mathrm{~b}$ is rejected because it's p-value greater than $0,05(0,960)$. This indicates that the implementation of the DS did not depend on the PoS. In more detail can be explained that when the number of suppliers is limited (less than three) and the competition among suppliers is low because the suppliers may supply their raw materials to many companies, then the wooden furniture owners did not necessary to implement DS. Therefore, the pressure from suppliers may not direct the wooden furniture owners to implement DS for example by, for examples produce more attractive, more varied, or much better wooden furniture than the competitors. The findings of this study support the findings of Bordean et al. (2011) [6] but are contrary to the findings of Lahiri (2007) [12] and Leitner \& Guildenberg (2010) [14].

Hypothesis 2c: Power of suppliers (PoS) significantly effects focus strategy (FS)

The hypothesis $2 \mathrm{c}$ is accepted because it's p-value is lower than $0,05(0,005)$. This implies that pressure from suppliers can direct the wooden furniture owners to implement FS. The pressure from suppliers may increase if the number of suppliers in the industry is limited (less than three), no tight competition among suppliers, and suppliers sale their raw materials to many companies. When the pressure from suppliers is high the owners of the wooden furniture will direct their sales to certain customers that prefer unique design or sale their products to certain market such as hospitals, schools, or other community groups. The findings of this study support the findings Bordean etl. (2011) [6] but are contrary to the findings of Leitner \& Guildenberg (2010) [14].

Hypothesis 3a: Threat of rivalries (ToR) significantly effects cost leadership strategy (CLS)

The hypothesis $3 \mathrm{a}$ is rejected because its $\mathrm{p}$-value is greater than $0,05(0,382)$. This indicates that the implementation of the CLS did not depend on the ToR. In more detail can be explained that when the competitors promote their product massively or when they perform price competition, the owners of wooden furniture did not necessary decide to implement CLS. Therefore, the pressure from rivalries cannot direct the owners to run their business more efficiently by cutting production costs such as raw materials, auxiliary materials, and labors. The findings of this study support the findings of Lahiri (2007) [12], but are contrary to the findings of Bordean et al. (2011) [6].

Hypothesis 3b: Threat of rivalries (ToR) significantly effects differentiation strategy (DS)

The hypothesis $3 \mathrm{~b}$ is accepted because it's p-value is lower than $0,05(0,00)$. This implies that pressure from rivalries can direct the wooden furniture owners to implement DS. The pressure from competitors such as promoting massively or price competition may guide the wooden furniture owners to implement DS by producing better product quality, more attractive products, more variety of products, and providing better service quality. The findings of this study support the findings of Ingga (2008) [10], and Bordean et al. (2011) [6] but are contrary to the findings of Lahiri (2007) [12] and Leitner \& Guildenberg (2010) [14].

Hypothesis 3c: Threat of rivalries (ToR) significantly effects focus strategy (FS)

The hypothesis $3 \mathrm{c}$ is accepted because its $\mathrm{p}$-value is lower than $0,05(0,001)$. This implies that pressure from rivalries can direct the wooden furniture owners to implement FS. The pressure from rivalries may increase if the competitors promote their products massively or they perform price competition. When the pressure from rivalries is high the owners of the wooden furniture will focus their sales to certain customers that prefer unique model or offer their furniture to certain group market such as universities, hospitals, or other group markets. The findings of this study support the findings of Ingga (2008) [10], and Bordean et al (2011) [6] but are contrary to the findings of Lahiri (2007) [12].

Hypothesis 4a: Cost-leadership strategy significantly effects firm performance (FP)

The hypothesis $4 \mathrm{a}$ is rejected because it's p-value is 0,224 which is greater than 0,05 . This indicates that the implementation of the CLS did not affect FP. In more detail can be explained that when the wooden furniture owners perform CLS by cutting their production costs such as raw material cost, auxiliary cost, and labor cost, firm performance like financial and market performance will not automatically increase. The findings of this study support the findings of Bordean et al. (2011) [6], but are contrary to the findings of Nandakumar et al. (2011) [16], Baroto et al. (2012) [4], Banker et al. (2014) [3].

Hypothesis 4b: Differentiation strategy (DS) significantly effects firm performance (FP)

The hypothesis $4 \mathrm{~b}$ is accepted because its $\mathrm{p}$-value is 0,000 which is lower than 0,05 . This implies that by producing more attractive and more variaty of wooden furniture, and also by providing much better products and services, the 
owners of wooden furniture can increase their financial and market performance. The findings of this study support the findings of Nandakumar et al. (2011) [16], Baroto et al. (2012) [4], Bordean et al. (2011) [6], and Banker et al. (2014) [3], but are contrary to the findings of Powers \& Hahn (2004) [22], and Leitner \& Guildenberg (2010) [14].

Hypothesis 4c: Focus strategy (FS) significantly effects firm performance (FP)

The hypothesis $4 \mathrm{c}$ is accepted because its p-value is 0,001 which is lower than 0,05 . This implies that by selling their products to certain markets such as to consumers that prefer unique furniture design or to certain market group such as schools, universities, banks, hospitals, and other group markets, the owners can increase their financial and market performance. The findings of this study support the findings of Bordean et al. (2011) [6], but are contrary to the findings of Powers \& Hahn (2004) [22], and Nandakumar et al. (2011) [16].

The research model based on the hypothesis results can be seen in the Figure 1 a as shown in the appendix 4.

\section{Conslusion}

From the hypothesis test results, it can be concluded that firstly, the implementation of the cost leadership strategy (CLS) depends on the pressure of suppliers, while the implementation of differentiation strategy (DS) depends on the pressure of buyers and rivalries, and the implementation of focus strategy (FS) depends on the pressure of suppliers and rivalries. Secondly, the implementation of differentiation strategy (DS) and focus strategy can increase financial and market performance, whereas there is no influence from the implementation of cost leadership strategy (CLS) on both financial and market performance. Therefore, the owners of wooden furniture are recommended to apply differentiation strategy (DS) when the pressure of buyers and threat from rivalries are high and execute focus strategy (FS) when the pressure of suppliers and threat from rivalries are high if the owners want to achieve their desired firm performance.

\section{Appendix 1}

Table 1. Outer Loadings.

\begin{tabular}{|c|c|c|c|c|c|}
\hline Items \& Latent Variables & Original Sample (O) & Sample Mean (M) & Standard Deviation (STDEV) & T Statistics (|O/STDEV|) & P Values \\
\hline $\mathrm{X} 1.1 .1<-\mathrm{PoB}$ & 0,639 & 0,645 & 0,237 & 2,697 & 0,007 \\
\hline $\mathrm{X} 1.1 .2<-\mathrm{PoB}$ & 0,749 & 0,773 & 0,214 & 3,503 & 0,001 \\
\hline $\mathrm{X} 1.1 .3<-\mathrm{PoB}$ & 0,872 & 0,730 & 0,225 & 3,878 & 0,000 \\
\hline $\mathrm{X} 1.2 .2<-\mathrm{PoS}$ & 0,337 & 0,289 & 0,402 & 0,839 & 0,402 \\
\hline $\mathrm{X} 1.2 .3<-\mathrm{PoS}$ & 0,840 & 0,766 & 0,223 & 3,773 & 0,000 \\
\hline $\mathrm{X} 1.3 .1<-\mathrm{ToR}$ & 0,921 & 0,847 & 0,180 & 5,120 & 0,000 \\
\hline $\mathrm{X} 1.3 .3<-\mathrm{ToR}$ & 0,624 & 0,620 & 0,230 & 2,716 & 0,007 \\
\hline Y1.1.1<- CLS & 0,917 & 0,797 & 0,274 & 3,352 & 0,001 \\
\hline Y1.1.2<- CLS & 0,879 & 0,778 & 0,255 & 3,443 & 0,001 \\
\hline Y1.1.3<- CLS & 0,639 & 0,593 & 0,376 & 1,699 & 0,090 \\
\hline $\mathrm{Y} 1.2 .1<-\mathrm{DS}$ & 0,805 & 0,818 & 0,036 & 22,121 & 0,000 \\
\hline $\mathrm{Y} 1.2 .2<-\mathrm{DS}$ & 0,821 & 0,829 & 0,035 & 23,376 & 0,000 \\
\hline $\mathrm{Y} 1.2 .3<-\mathrm{DS}$ & 0,838 & 0,823 & 0,031 & 27,417 & 0,000 \\
\hline $\mathrm{Y} 1.2 .4<-\mathrm{DS}$ & 0,748 & 0,747 & 0,051 & 14,577 & 0,000 \\
\hline Y1.3.2<- FS & 0,916 & 0,914 & 0,021 & 42,778 & 0,000 \\
\hline Y1.3.3<- FS & 0,914 & 0,914 & 0,014 & 64,389 & 0,000 \\
\hline Y $2.1<-$ FP & 0,948 & 0,947 & 0,015 & 63,374 & 0,000 \\
\hline $\mathrm{Y} 2.2<-\mathrm{FP}$ & 0,962 & 0,960 & 0,013 & 73,113 & 0,000 \\
\hline $\mathrm{Y} 2.3<$ - FP & 0,727 & 0,720 & 0,063 & 11,493 & 0,000 \\
\hline
\end{tabular}

Source: Smart PLS 3 (2016)

\section{Appendix 2}

Table 2. Composite Reliability.

\begin{tabular}{|c|c|c|c|c|c|}
\hline Latent Variables & Original Sample (O) & Sample Mean (M) & Standard Deviation (STDEV) & T Statistics (|O/STDEV|) & P Values \\
\hline CLS & 0,858 & 0,796 & 0,160 & 5,370 & 0,000 \\
\hline DS & 0,879 & 0,880 & 0,017 & 53,263 & 0,000 \\
\hline FP & 0,915 & 0,913 & 0,012 & 74,177 & 0,000 \\
\hline FS & 0,938 & 0,937 & 0,009 & 102,059 & 0,000 \\
\hline PoB & 0,801 & 0,770 & 0,125 & 6,412 & 0,000 \\
\hline PoS & 0,565 & 0,502 & 0,218 & 2,589 & 0,010 \\
\hline ToR & 0,699 & 0,667 & 0,146 & 4,788 & 0,000 \\
\hline
\end{tabular}

Source: Smart PLS 3 (2016) 


\section{Appendix 3}

Table 3. Path Coefficients.

\begin{tabular}{|c|c|c|c|c|c|c|}
\hline Variables & Original Sample (O) & Sample Mean (M) & Standard Deviation (STDEV) & T Statistics (|O/STDEV|) & P Values & Remark \\
\hline CLS -> FP & 0,112 & 0,100 & 0,092 & 1,218 & 0,224 & NS \\
\hline DS $->$ FP & 0,310 & 0,312 & 0,074 & 4,213 & 0,000 & $\mathrm{~S}$ \\
\hline FS -> FP & 0,237 & 0,238 & 0,076 & 3,114 & 0,002 & $\mathrm{~S}$ \\
\hline PoB $->$ CLS & 0,169 & 0,142 & 0,128 & 1,320 & 0,188 & NS \\
\hline PoB -> DS & $-0,314$ & $-0,297$ & 0,092 & 3,400 & 0,001 & $\mathrm{~S}$ \\
\hline PoB $->$ FS & $-0,024$ & $-0,025$ & 0,082 & 0,293 & 0,769 & NS \\
\hline PoS -> CLS & $-0,314$ & $-0,297$ & 0,092 & 3,400 & 0,001 & $\mathrm{~S}$ \\
\hline PoS $->$ DS & $-0,008$ & 0,009 & 0,158 & 0,050 & 0,960 & NS \\
\hline PoS $->$ FS & $-0,235$ & $-0,233$ & 0,084 & 2,808 & 0,005 & $\mathrm{~S}$ \\
\hline ToR -> CLS & 0,103 & 0,118 & 0,118 & 0,874 & 0,382 & NS \\
\hline ToR $->$ DS & 0,312 & 0,319 & 0,086 & 4,224 & 0,000 & $\mathrm{~S}$ \\
\hline ToR $->$ FS & 0,300 & 0,296 & 0,092 & 3,246 & 0,001 & $\mathrm{~S}$ \\
\hline
\end{tabular}

Note: $\mathrm{S}=$ Significant; NS $=$ Not Significant

Source: Smart PLS 3 (2016)

\section{Appendix 4}

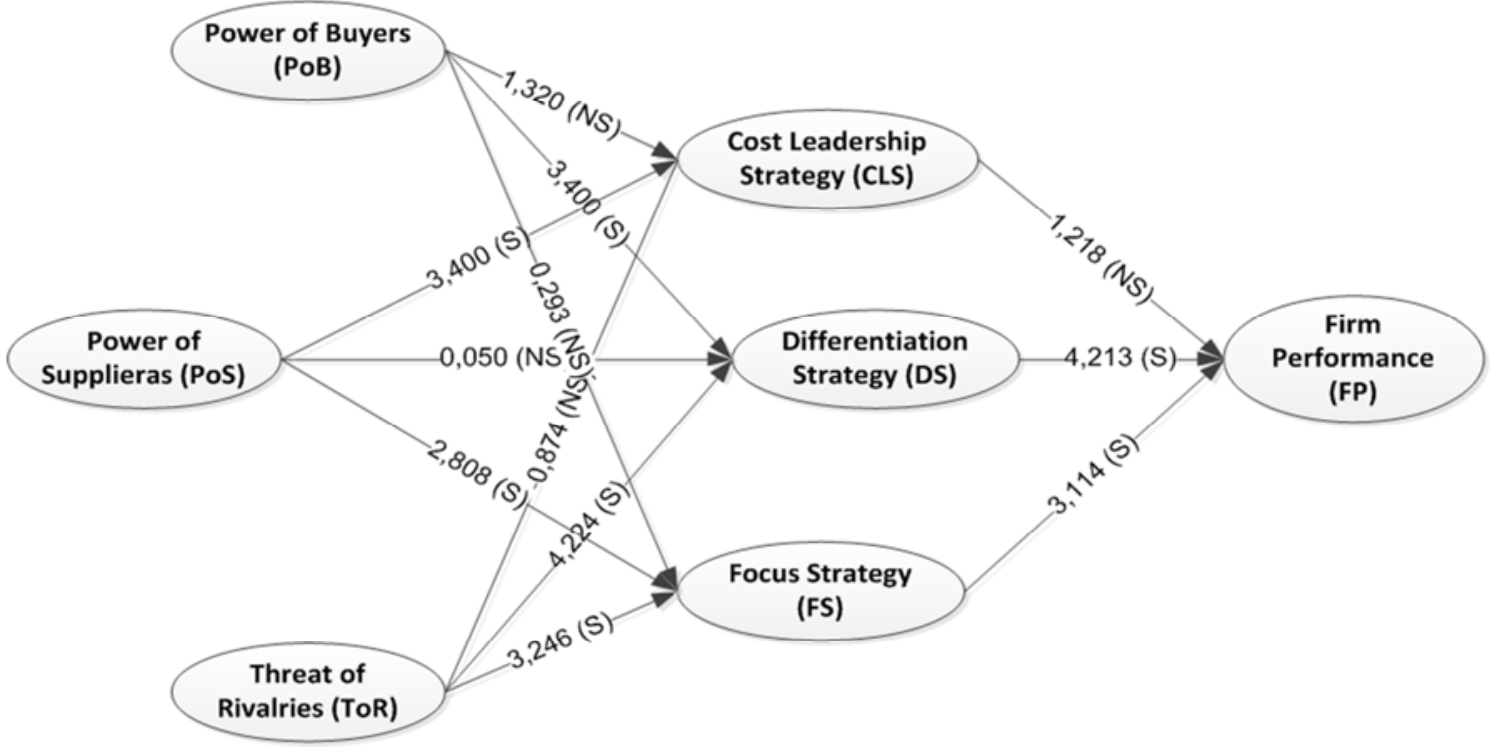

Figure 1. Research Model.

\section{References}

[1] Adidam, P. T., Banerjee, M., and Shukla, P. (2012). Competitive intelligence and firm's performance in emerging markets: an exploratory study in India. Journal of business and industrial marketing, 27 (3), 242-254.

[2] Asika, N. (1991), Research Methodology in the Behavioural Sciences. Nigeria: Longman, (Chapter Five).

[3] Banker, R. D., Mashruwala, R., and Tripathy, A. (2014). Does a differentiation strategy lead to more sustainable financial performance than acost leadership strategy? Management Decision, Vol. 52 (5), 872-896.

[4] Baroto, M. B., Abdullah, M. M. B., and Wan, H. L. (2012). Hybrid Strategy: A New Strategy for Competitive Advantage. International Journal of Business and Management, Vol. 7 (20), 120-133.
[5] Baum, J. R., Edwin, A., Locke, E. A., \& Ken, S. G. (2001). A Multidimensional Model of Venture Growth. Academic Management Journal. 44 (2), 292-303.

[6] Bordean, O. N., Borza, A., \& Segura, D. G. (2011). A comparative approach of the generic strategies within the hotel industry: Romania VS. USA. Management and Marketing Challenges for the Knowledge Society. Vol. 6 (4), 501-514.

[7] Dauda, Y. A.; Akingbade, W. A.; and Akinbali, H. B. (2010). Strategic management practice and corporate performance of selected small business enterprises in Lagos Metropolis. International Journal of Business and Management, 5 (11), 97-105.

[8] East Java Statistical Bureau Center. (2013). Indonesia furniture export in 2012 based on the provinces' contributions.

[9] Herri and Wafa, S. A. (2003). The Influence of Internal and External Factors on the Performance of Indonesian SMEs. 
[10] Ingga, I (2008). The effect external environments, Internal environments, cost leadership strategy, and differentiation strategy on customer value and competitive advantage. Unpublished dissertation. Brawijaya University, Malang.

[11] Karel, S., Adam, P., and Radomir, P. (2013). Strategic planning and business performance of micro, small and medium-sized enterprises. Journal of competitiveness, vol. 5 (4), 57-72.

[12] Lahiri, S. (2007). Industry-Level Competitive Forces, Firm Resource, Strategy, and Performance: An Investigation of Indian Business Process Outsourcing Providers. Unpublished Dissertation, the University of Memphis.

[13] Latan, H., \& Ghozali, I. (2012), Partial Least Square: Consept, Technique and Aplication. Semarang: Badan Penerbit Undip.

[14] Leitner, K. H., and Guildenberg. (2010). Generic strategies and firm performance in SMEs: a longtidunal study of Austrian SMEs. Small Business Economics, 35: 169-189.

[15] Levine, N., \& Ross, J. W. (2003). From the vendor's perspective: Exploring the value proposition in information technology outsourcing. Management Information System Quarterly, 27 (3), 331-364.

[16] Nandakumar, M. K., Ghobadian, A., and O’Regan, N. (2011). Generic strategies and performance - evidence from manufacturing firms. International Journal of Productivity and Performance Management, Vol. 60 (3), 222-251.

[17] Nasikh, S. (2015). The value of non-oil exports in East Java, access online on 10th July 2015 from www.republika.co.id.

[18] Omsa, S., Salim, U., Djumahir., and Rahayu, M. (2015).
Competitive strategy orientation and company performance in selected SMEs Wooden Furniture in Pasuruan city. International Journal of Applied Business and Economic Research (IJABER), 13 (7), 4659-4676.

[19] Parnel, J. A., \& Hershey, L. (2005). The strategy-performance relationship revisited: The blessing and curse of the combination strategy. International Journal of Commerce and Management, 75 (1), 17-33.

[20] Pearce, J. A., \& Robinson, J. R. (2009). Strategic Management: Formulation, Implementation and Control (11th Ed.). New York: The McGraw-Hill Companies, Inc.

[21] Porter, M. E. (1985). Competitive Advantage: Creating and Sustaining Superior Performance, New York: Free Press.

[22] Powers, T. L., and Hahn, W. (2004). Critical competitive methods, generic strategies, and firm performance. The International Journal of Bank Marketing, Vol. 22 (1), 43-63.

[23] Shane, S., \& Kolvereid, L. (1995). National Environment, Strategy, and new Venture Performance: A Three Country Study. Journal of Small Business Management, 33 (2), 37-51.

[24] Wan, Z., \& Bullard, S. H. (2009), "Competitive Strategy and Business Performance in the US. Upholstered, Wood Household Furniture Industry". Forest Product Journal, 59 (9), 5-19

[25] Yani, A. (2010). Competitive advantage trough strategy approach in Islamic banks in South Kalimantan. Unpublished dissertation. Brawijaya University, Malang.

[26] Yonggui, W., Yuli, Z., \& Hing-P, L. O. (2003). The Key Factors Distinguishing High-Growth SME from Those Poor Performance: Evidence from China. 